\title{
CONTROLE AUTOMÁTICO DE GAP PARA PRENSA DE ROLOS*
}

\author{
Marcelo de Castro Souza ${ }^{1}$ \\ Cristian Herbert Cypriano Gonçalves ${ }^{2}$ \\ Paulo Henrique Cardoso Mendes ${ }^{3}$ \\ Gustavo Ferreira Viana ${ }^{4}$ \\ Renato Luciano Araujo de Meneses ${ }^{5}$
}

\section{Resumo}

Neste artigo é descrito o desenvolvimento e implementação de uma nova estratégia de controle para Prensa de Rolos Polycom da POLYSIUS, utilizada no processo de pelotização da Samarco Mineração S.A. A estratégia de controle é redesenhada com objetivo de otimizar o processo e aumentar a eficiência do equipamento. Como resultado do trabalho foi verificado um aumento significativo da superfície específica do pellet feed de saída.

Palavras-chave: Controle cascata; Prensa de rolos; Mineração; Estratégia de controle.

\section{Abstract}

\section{AUTOMATIC CONTROL FOR ROLLER PRESS GAP}

This paper describes the development and implementation of a new control strategy for Roller Press used in the pelletizing process of Samarco Mineração S.A. The control strategy is redesigned in order to optimize the process and increase equipment efficiency. As a result of work a significant increase has been seen in the specific surface of output pellet feed.

Keywords: Cascade control; Roller press; Mining; Control strategy.

1 Técnico Automação Industrial, Técnico, Técnico de Automação, Gerência de Engenharia de Processo e Automação, Samarco Mineração S.A, Anchieta, Espirito Santo, Brasil.

2 Técnico Automação Industrial, Técnico, Técnico de Automação, Gerência de Engenharia de Processo e Automação, Samarco Mineração S.A, Anchieta, Espirito Santo, Brasil.

3 Engenharia de Controle e Automação, Engenheiro, Engenheiro de Automação, Gerência de Engenharia de Processo e Automação, Samarco Mineração S.A, Anchieta, Espirito Santo, Brasil.

4 Engenharia Elétrica, Engenheiro, Engenheiro de Automação, Gerência de Engenharia de Processo e Automação, Samarco Mineração S.A, Anchieta, Espirito Santo, Brasil.

5 Engenharia Metalúrgica, Engenheiro, Engenheiro de Processo, Gerência de Produção, Samarco Mineração S.A, Anchieta, Espirito Santo, Brasil. 


\section{INTRODUÇÃO}

A prensa de rolos é utilizada na Samarco Mineração S.A para cominuição do pellet feed com o objetivo de aumentar a superfície específica do material, propiciando uma melhor formação e acabamento da pelota de ferro. Este equipamento é composto por dois rolos paralelos que giram em sentidos opostos e são separados por uma distância denominada gap (Figura 1). O movimento de rotação faz com que o material escoe entre os rolos se sujeitando a uma força de cominuição.

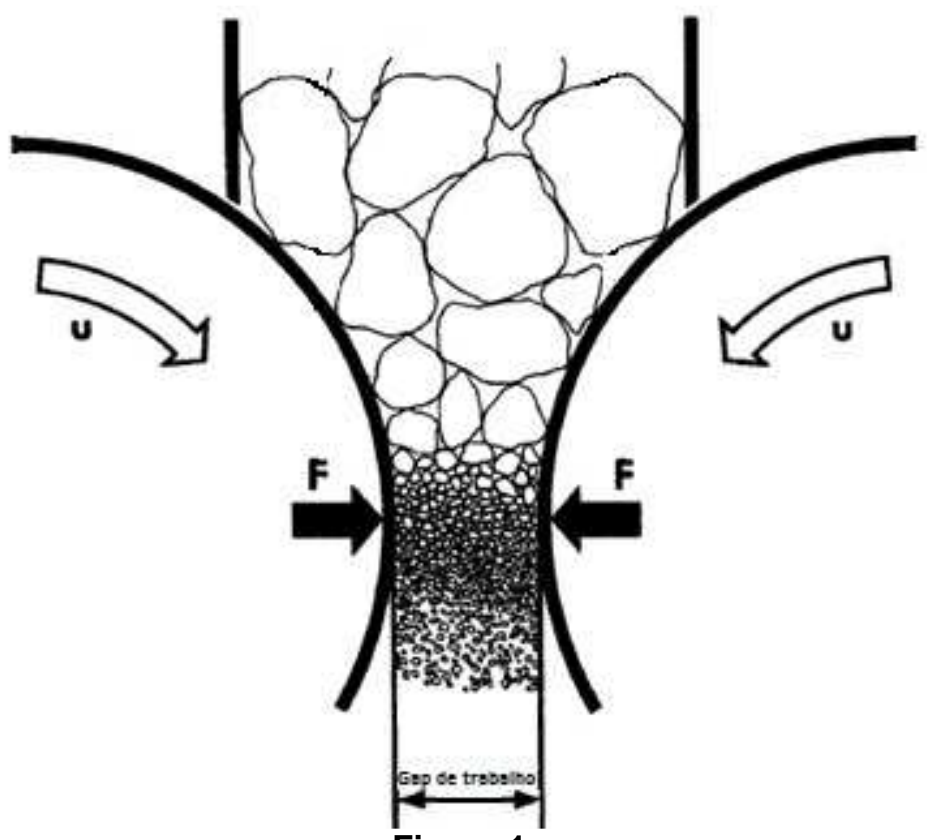

Figura 1

A força específica de moagem depende da pressão exercida e do gap de trabalho. Dessa maneira, respeitando os limites máximo e mínimo do espaçamento entre os rolos, quanto maior a pressão aplicada maior a força específica de moagem.

A variação das propriedades do minério que alimenta a prensa faz com que o gap oscile mesmo quando uma pressão constante é aplicada aos rolos. Dessa forma, é necessário que o operador ajuste continuamente o processo para que o gap se mantenha dentro dos limites e a pressão aplicada seja sempre a maior possível.

O trabalho realizado na prensa de rolos da $3^{\underline{a}}$ Usina da Samarco Mineração S.A, buscou otimizar o controle da prensa evitando que o gap permaneça fora dos limites desejáveis e opere sempre com a maior pressão possível, de modo a melhorar a qualidade do material processado pelo equipamento.

\section{MATERIAIS E MÉTODOS}

\subsection{Caracteristicas do Processo}

Primeiramente, para o desenvolvimento do trabalho, estudamos o equipamento e cada um dos seus parâmetros operacionais em detalhes com o propósito de se conhecer a relação entre eles e a dinâmica de seus comportamentos. Os principais parâmetros levantados foram: GAP Zero; GAP Máximo; GAP de Trabalho; Nível da Calha de Alimentação; Rotação dos rolos; e, Pressão Aplicada aos Rolos. 
Gap Zero é a distância mínima entre os rolos. Quando o equipamento opera com esta abertura a pressão deixa de ser aplicada sobre o material que escoa entre eles e passa a ser aplicada a um batente existente que dissipa grande parte da energia que seria utilizada para cominuir o material. Portanto, é importante para a eficiência do equipamento operar sempre acima do gap zero. Acresce que o gap zero deve ser ajustado fisicamente de forma a garantir que toda a pressão aplicada pelos rolos seja dissipada no material a ser cominuído e não na estrutura do equipamento.

Gap máximo não é um parâmetro físico do processo. Sabe-se que à medida que o gap aumenta para uma mesma pressão, a força específica de moagem é aplicada a uma quantidade maior de material, em virtude disso, a eficiência do equipamento é reduzida. Assim sendo, deve-se buscar sempre o menor gap possível, situação esta onde a pressão é transmitida a menor quantidade possível de material resultando em melhores eficiências.

Gap de trabalho é a abertura existente entre os rolos durante a operação do equipamento. É desejável que este gap permaneça entre o gap mínimo e máximo para garantir a maior eficiência do equipamento.

A calha de alimentação é um pequeno silo de material existente à cima dos rolos (Figura 2) responsável por manter o equipamento constantemente abastecido de material para ser processado. O nível desta calha é uma das variáveis que influenciam no processo de prensagem. Foi observado que um nível muito baixo faz com que o material ofereça pouca resistência a pressão dos rolos permitindo que o gap seja reduzido até o gap mínimo caso a pressão não seja reajustada, sendo necessário operar sempre com o maior nível possível.

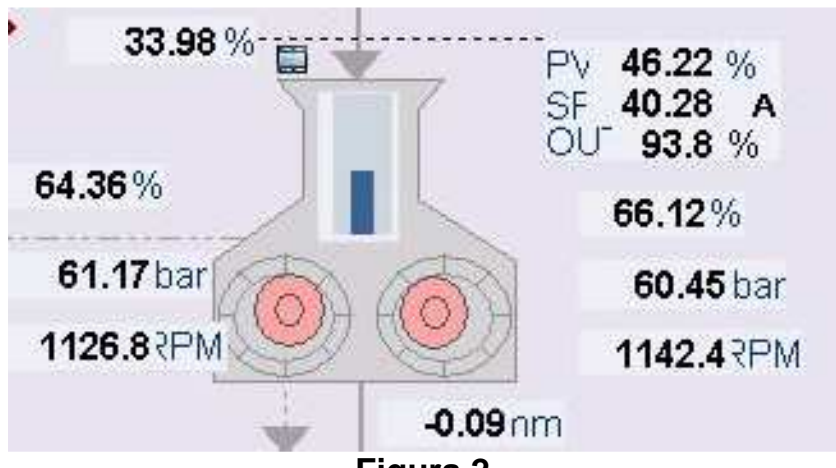

Figura 2

A rotação dos rolos também é de extrema importância e está diretamente relacionada à produtividade do equipamento. Apesar de altas rotações fornecerem produtividade mais alta, elas reduzem o tempo de permanência do material entre os rolos reduzindo assim os ganhos de superfície específica.

A pressão hidráulica aplicada aos rolos, de fato, é o parâmetro mais importante do processo haja vista que ela é a responsável pela força específica de moagem que irá cominuir o pellet feed aumentando sua superfície específica. Observa-se que, respeitando os limites do gap, quanto maior a pressão hidráulica melhores serão os resultados de qualidade do material processado pelo equipamento.

Outro parâmetro que afeta significativamente o processo é a característica do minério. Fatores como a umidade, composição química e física do pellet feed influenciam diretamente no comportamento do processo e não necessariamente de uma maneira linear. 


\section{2 - Caracteristicas do Controle}

Após conhecer o funcionamento do equipamento e seus parâmetros fundamentais, estudamos as malhas de controle existentes no processo.

O processo possui um controlador proporcional e integral (PI) e um automatismo para controle de pressão, já configurados por linguagem de blocos no sistema de controle Delta $\mathrm{V}$ da Emerson Process Management, que funcionavam da seguinte maneira:

O PI (Figura 3) controla o nível da calha de alimentação da prensa atuando na rotação dos rolos. Este controle possui uma alta complexidade, principalmente por consequência de sua linearidade se alterar em função da umidade entre outras características do material de entrada. Além disso, caso o nível chegue em 100\% o equipamento é intertravado por questões de segurança.

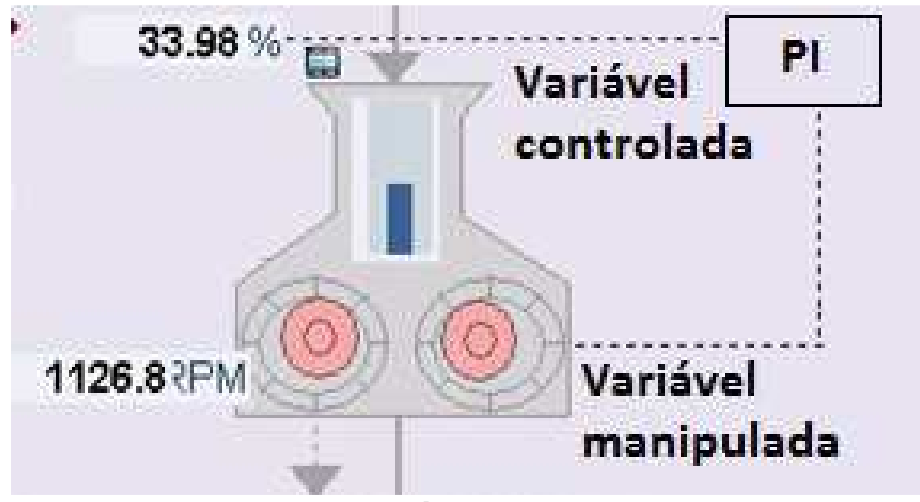

Figura 3

O controle de pressão (Figura 4) funciona por meio de uma linha de óleo pressurizado e um sistema de válvulas solenódes, onde o operador estabelece manualmente uma pressão máxima e mínima desejada. Desse modo, ao atingir a pressão mínima o sistema abre as válvulas de pressurização a fim de permitir a passagem de óleo para o rolo da prensa por um tempo pré-definido, pressurizando novamente o equipamento. De maneira analoga, ao se atingir a pressão máxima o sistema abre as válvulas de alívio que retornam o óleo ao tanque, aliviando a pressão dos rolos. O operador observa o gap de trabalho, o nível da calha e a rotação dos rolos para tomar a decisão de deslocar o range de pressão para cima ou para baixo. Infelizmente algumas vezes em função de ter outras demandas o operador perde oportunidades de se aumentar a pressão de trabalho do equipamento ou até mesmo deixa de aliviar a pressão fazendo com que acumule material na calha saturando assim a malha que controla o nível e causando a parada de todo o processo. 


\section{$19^{\circ}$ Automação \& TI}

ISSN: 2237-0234

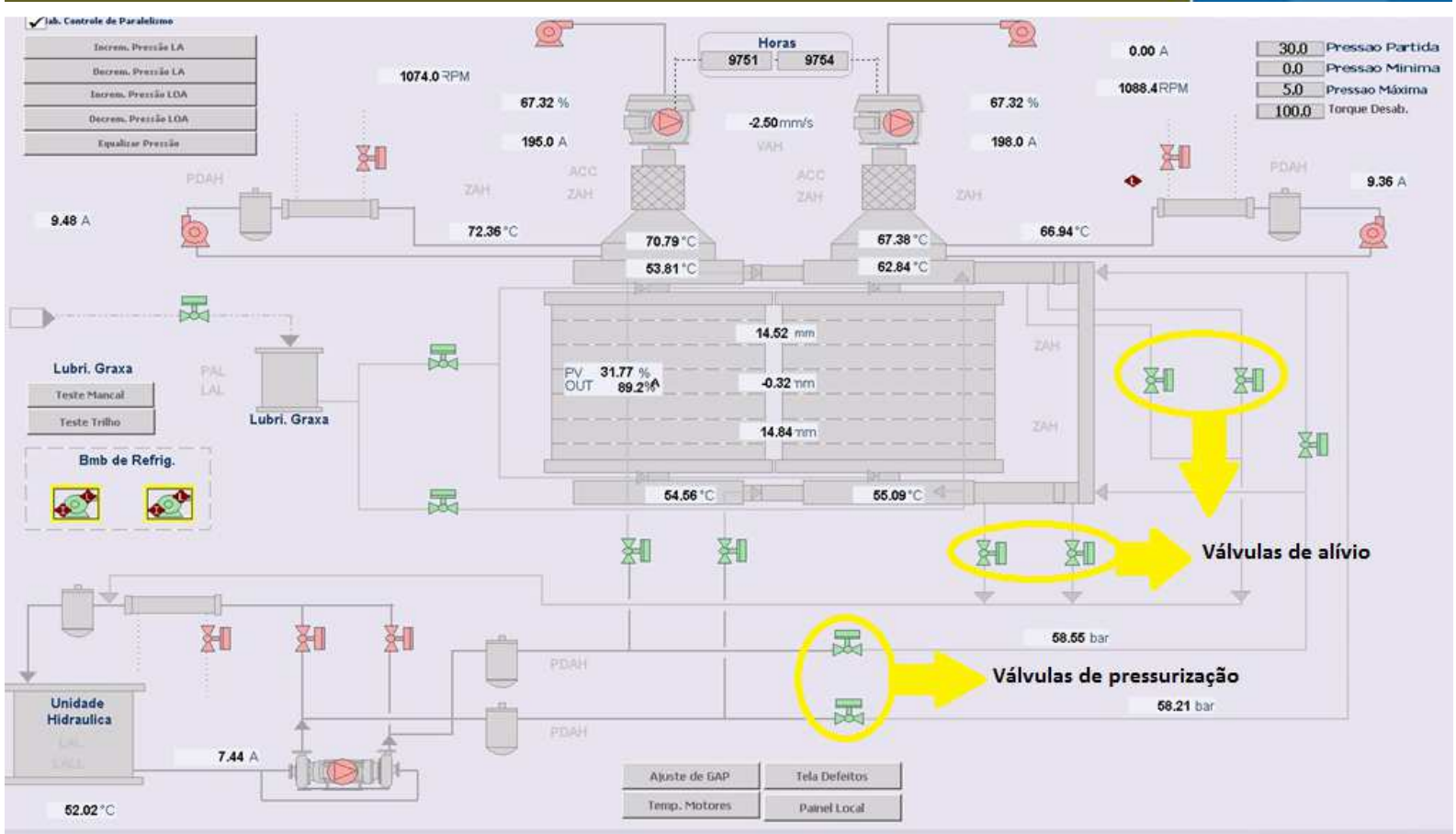

Figura 4

\section{3 - Desenvolvimento do CoIntrole Automático}

A solução para aumentar a eficiência do processo e minimizar estes problemas foi alterar a estratégia de controle utilizada. Desta forma, foi proposto a utilização de controladores PIDs alocados conforme a figura 5.

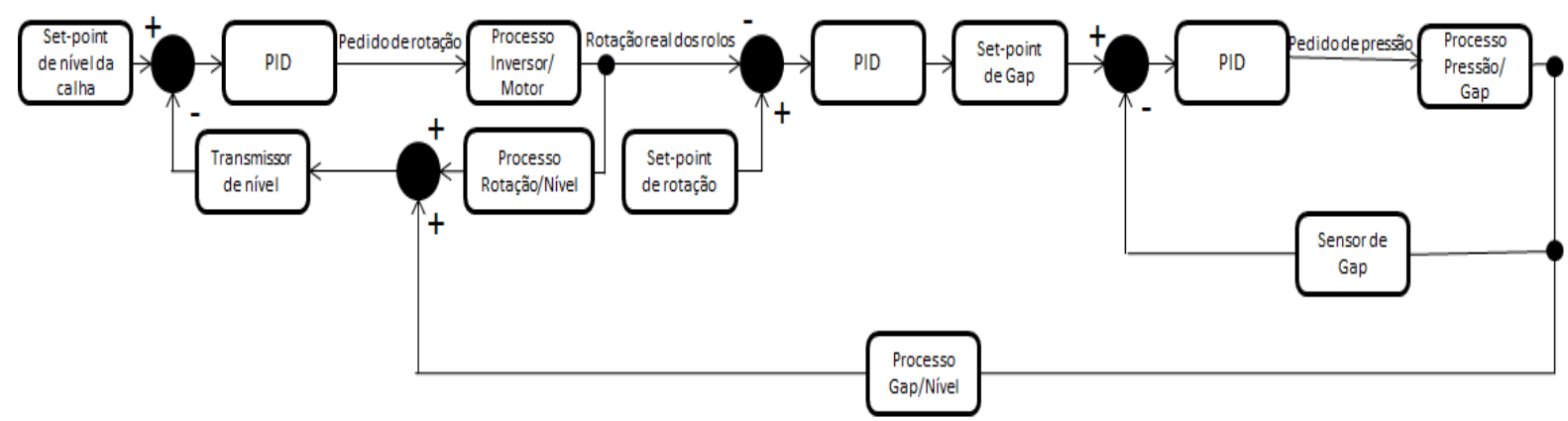

Figura 5

O controlador responsável pelo nível da calha é mantido, entretanto a rotação dos rolos passa a ser utilizada também para se controlar o gap de trabalho. O objetivo deste controle é aumentar o espaçamento entre os rolos caso a malha de controle de nível da calha esteja saturada com a rotação próxima a 100\%, e reduzir o gap quando a rotação dos rolos decrementar, indicando que é possível manter a produtividade do equipamento mesmo reduzindo o gap de trabalho, para que esse controle funcione apropriadamente o set-point de rotação deve ser próximo de $100 \%$.

O pedido de gap é utilizado como set-point de um terceiro controlador. Esse controlador é responsável pelo espaçamento entre os rolos atuando nos limites de pressão do automatismo já existente, fazendo com que as pressões mínimas e máximas sejam incrementadas igualmente quando um gap menor se faz necessário, 
mas sem alterar a diferença de pressão existente entre os limites. Da mesma forma, quando é necessário aumentar o gap as pressões máxima e mínima são decrementadas.

O controle desenvolvido visa o aproveitamento máximo do equipamento antecipando as ações que seriam tomadas pela atuação manual do operador.

\section{RESULTADOS E DISCUSSÂO}

Para medir o desempenho do equipamento utilizamos uma análise de regressão com dados históricos do processo onde foi possível, por meio da umidade e da superfície específica (SE) do material de entrada, estimar uma superfície específica esperada na saída. Segue equação obtida:

$$
S E_{\text {saída esperada }}=K_{1}+K_{2} \cdot H_{2} O_{\text {entrada }}+K_{3} \cdot S E_{\text {entrada }}+K_{2} \cdot H_{2} O_{\text {entrada }} \cdot S E_{\text {entrada }} \text { (1) }
$$

Obs: $\boldsymbol{R}^{2}=\mathbf{0 , 9 0}$

Sendo SE a superfície específica do minério, $K_{1}, K_{2} e K_{3}$ os parâmetros obtidos na análise de regressão com dados históricos do processo e $\boldsymbol{H}_{2} \boldsymbol{O}$ a umidade do material.

Por fim, para medir a eficiência do processo simplesmente dividimos a superfície real pela esperada, conforme equação abaixo:

$$
\text { Eficiência }=\frac{S E_{\text {saída real }}}{S E_{\text {saída esperada }}}(2)
$$

Utilizando este indicador foi realizado um teste onde desligamos e ligamos (teste on/off) a estratégia de controle desenvolvida durante determinados períodos de tempo. Os resultados são evidenciados na figura 6 abaixo:

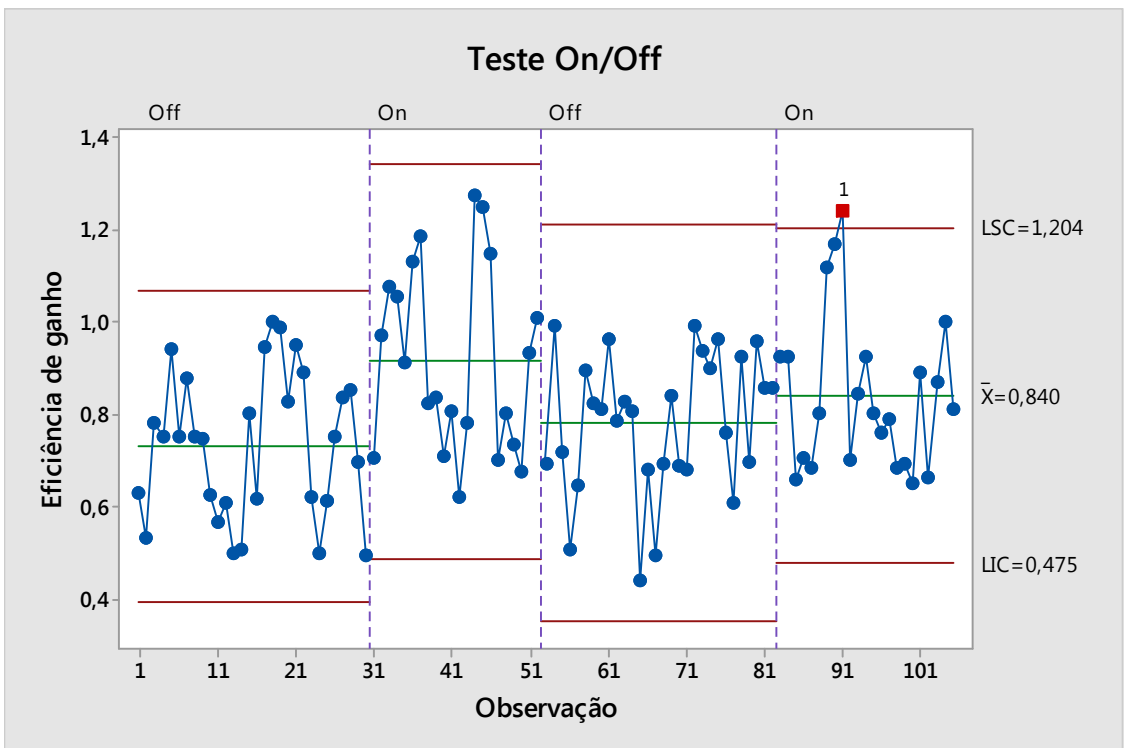

Figura 6

O desempenho do indicador utilizado sofreu um incremento de $18 \%$ em relação à condição anterior, saindo de $72 \%$ para aproximadamente $85 \%$ (Figura 7) evidenciando os ganhos com a nova estratégia de controle. Além disso, o desvio padrão foi reduzido em 16\% (Figura 7) trazendo mais estabilidade para o processo. 
A nova estratégia de controle se mostrou eficaz uma vez que é incrementa a pressão de trabalho sempre que possível, aumentando assim a força média aplicada ao pellet feed resultando em uma melhor cominuição do material.

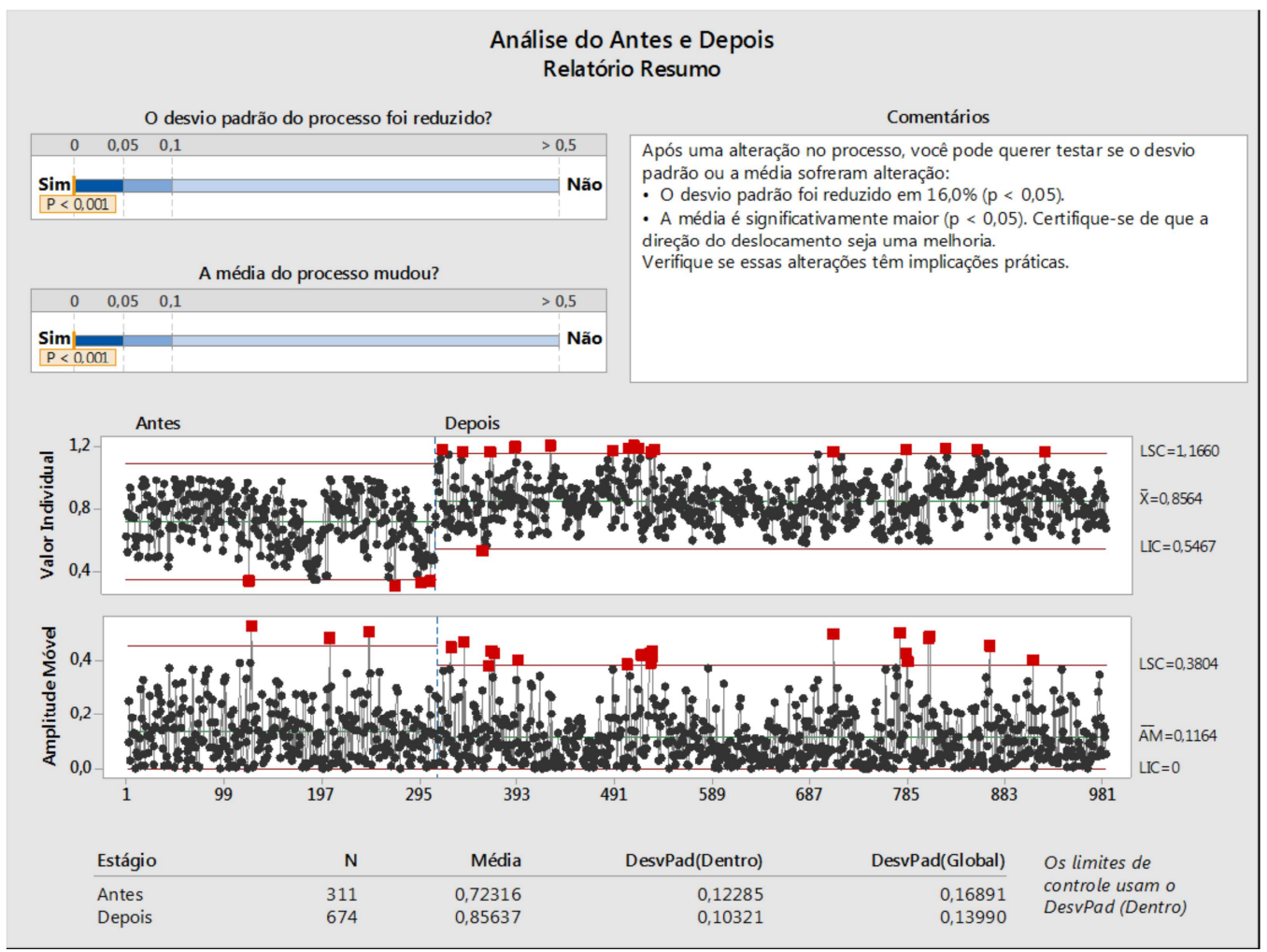

Figura 7

\section{CONCLUSÃo}

De acordo com os resultados alcançados, bem como a revisão bibliográfica realizada, podemos afirmar que a nova estratégia de controle aplicada ao processo de prensagem de pellet feed provocou um aumento considerável na eficiência do equipamento, incrementando a superfície específica do material processado, melhorando a qualidade do produto final da Samarco Mineração S.A.

O controle foi apresentado ao representante técnico da POLYSIUS, que ficou entusiasmado com o desempenho do equipamento após implantação do controle.

Este controle já foi replicado para prensa de rolos da 4⿳亠丷厂 Usina de Pelotização, e foi iniciado um estudo para implantação deste mesmo controle nas usinas 1 e 2 da Samarco Mineração S.A.

\section{Agradecimentos}

Agradeço a toda equipe envolvida no desenvolvimento deste controle, principalmente aos engenheiros envolvidos neste trabalho que deram todo o suporte teórico e prático, e aos técnicos de automação pelo empenho e dedicação desprendido durante todo o processo. 


\section{BIBLIOGRAFIA}

1 Campos, Mario Cersar M. Massas de; Teixeira Herbert C.G. Controles Típicos de Equipamentos e Processos Industriais. 2. Ed. São Paulo:Blucher. 2010.

2 Blevins, Terrence L.; McMillan, Gregory K.; Wojsznis, Willy K.; Brown, Michael W. Advanced Control Unleashed - Plant Performance Management for Optimum Benefit. ISA. 2003

3 Samarco Mineração SA. Manual Intergrado da Gerência de Produção de Ubu. 2013. Revisão 01:34-38 